\title{
Preliminary Assessment for Attitudes of Medical Students to Doctor-Patient Communication
}

\author{
Da Liu ${ }^{1}$, Longwen $\mathrm{Xu}^{2}$, Zhaoyang Yin ${ }^{1}$, Yayu Huang ${ }^{3}, \mathrm{Li} \mathrm{Xu}^{4}$, * \\ ${ }^{1}$ Aerospace Medicine Institute, Fourth Military Medical University, Xi'an, China \\ ${ }^{2}$ Department of Oncology, Xijing Hospital, Fourth Military Medical University, Xi' an, China \\ ${ }^{3}$ Department of Internal Medicine Teaching, Xijing Hospital, Fourth Military Medical University, Xi'an, China \\ ${ }^{4}$ Department of Gastroenterology, Xijing Hospital, Fourth Military Medical University, Xi'an, China
}

Email address:

lxuhelen@163.com(Li Xu)

${ }^{*}$ Corresponding author

\section{To cite this article:}

Da Liu, Longwen Xu, Zhaoyang Yin, Yayu Huang, Li Xu. Preliminary Assessment for Attitudes of Medical Students to Doctor-Patient Communication. Science Journal of Education. Vol. 4, No. 3, 2016, pp. 113-117. doi: 10.11648/j.sjedu.20160403.11

Received: April 3, 2016; Accepted: April 16, 2016; Published: July 15, 2016

\begin{abstract}
Effective doctor-patient communication is essential for delivering high quality patient care and building harmonious doctor-patient relationship. However, little is known about student's assessment of doctor-patient relationship and their attitudes towards their own communication skills and participating in communication skills courses. The aim of the present study was to identify these assessment and attitudes prior to commencing such a course. We conducted a survey using a self-designed questionnaire on 363 undergraduate medical students in an anonymous way. More than half of the undergraduate medical students (64.7\%) thought the doctor-patient relationship is relatively harmonious and $75.5 \%$ felt that good doctorpatient communication skills could effectively reduce the incidence of current medical disputes. $81.3 \%$ of medical students believed that their communication skills are limited, and are eager to be trained, but only $33.2 \%$ of the students agreed that communication curriculum should become a compulsory course. $53.7 \%$ of the students favored interactive lectures over the didactic formal lectures. Based on the survey, we feel that it is necessary to setup the doctor-patient communication curriculum in medical institutions to enhance the communication ability of medical students. The preferred teaching style is through interactive lectures with opportunities for discussion and observation.
\end{abstract}

Keywords: Medical Student, Doctor-Patient Relationship, Doctor-Patient Communication

\section{Introduction}

In spite of the miraculous advance of medicine during the past century, it does not come with a concomitant increase in the public's satisfaction with the medical profession $[1,2]$. This is particularly the case in China. Doctors in China are facing a relatively complex situation nowadays $[3,4,5]$. Much of the medical disputes relates to problems in doctorpatient communication $[6,7,8]$. Moreover, some patients in China take it for granted that once they pay the money, they should be cured. This places enormous demands on doctors.

Although there is no golden standard on 'good doctor', superb medical skills, noble medical ethics, as well as good doctor-patient communications, are favored. Good relationship building, facilitating patients' compliance are core elements of so-called 'good doctor-patient communication' [9]. There has been evidence that effective doctor-patient communication is related to better health outcomes, better cooperation and higher satisfaction of both doctors and patients $[10,11,12,13]$. Therefore, many medical universities in the advanced countries already incorporate doctor-patient communication skill training into medical curricula $[14,15,16]$. However, the current education for doctor-patient communication in China is relatively insufficient $[17,18]$. For example, in some schools, the communication syllabus is presented mainly through didactic lectures with limited several hours. How to make medical students become proficient in communication skills and applied to medical practice is a problem that worth reflection in the cultivation of medical students in China. The 
major objective of this study was to understand undergraduate medical students' assessment and attitudes towards doctor-patient communication, with a view to considering future strategies for providing doctor-patient communication training in medical universities.

\section{Methods}

\subsection{Participants}

Using a self-designed questionnaire, we carried out the current study in 2014 among 363 undergraduate medical students. The survey was done anonymously. We distributed the questionnaires to 363 enrolled third-year medical students and 343 students appropriately completed the questionnaires.

\subsection{Ethical Approval}

Permission was granted from the Dean of Medical Sciences that third-year medical students could be approached and asked if they would take part in the study. The questionnaire was distributed with an explanation of its purpose to students who gave their informed consent to be part of the study.

\subsection{Questionnaire}

The questionnaire mainly included the following information: cognition of the current doctor-patient relationship, influence of the doctor-patient communication on overall medical disputes, evaluation of their own ability of doctor-patient communication and attitudes towards teaching style for setting up the doctor-patient communication curriculum.

\section{Results}

\subsection{Cognition of Current Doctor-Patient Relationship}

As shown in Table 1, among the surveyed third-year medical students, only $2.0 \%$ felt that the doctor-patient relationship is very harmonious, while $35.3 \%$ thought the relationship is tense. $64.7 \%$ of the students viewed the relationship as relatively harmonious with potential problems.

Table 1. Cognition of current doctor-patient relationship.

\begin{tabular}{lll}
\hline Choices & Number of Students & Percentage \\
\hline Very Harmonious & 7 & 2.04 \\
Relatively Harmonious & 215 & 62.68 \\
Tense & 121 & 35.28 \\
Total & 343 & 100.0 \\
\hline
\end{tabular}

\subsection{Attitudes Toward the Influence of Doctor-Patient Communication on Medical Disputes}

From the survey results (as shown in Table 2), 75.5\% of the students thought good communication skills could effectively reduce the incidence of medical disputes, $22.7 \%$ felt it is helpful to a certain extent, while under $2 \%(1.75 \%)$ hold the opposite attitude that it exerts no influence.

Table 2. Attitudes to the influence of doctor-patient communication on medical disputes.

\begin{tabular}{lll}
\hline Choices & Number of Students & Percentage \\
\hline Very Influential & 259 & 75.51 \\
Certain Influence & 78 & 22.74 \\
No Influence & 6 & 1.75 \\
Total & 343 & 100.0 \\
\hline
\end{tabular}

\subsection{Evaluation of Their Own Doctor-Patient Communication Ability}

We could see from the survey results (Table 3 ) that less than $20 \%$ of the surveyed medical students (18.7\%) thought they are capable of communicating effectively with patients, while majority of the students $(81.3 \%)$ felt that their communication ability is limited $(65.9 \%)$, with defects $(11.7 \%)$ or do not have the ability (3.8).

Table 3. Evaluation of their own doctor-patient communication ability.

\begin{tabular}{lll}
\hline Choices & Number of Students & Percentage \\
\hline Have the Ability & 64 & 18.66 \\
Have Certain Ability & 226 & 65.89 \\
Have the Ability with Defects & 40 & 11.66 \\
Do not Have the Ability & 13 & 3.79 \\
Total & 343 & 100.0 \\
\hline
\end{tabular}

\subsection{Attitudes Toward Whether Communication Courses Should Be Setup}

In consistence with the above students' awareness of their communication skill level, most medical students (82.2\%) believed that the setting up an education program about the doctor-patient communication was essential (Table 4). About $5.00 \%$ of students felt that it was unnecessary, as in their thoughts; communication skills are only learned by experience and not taught formally.

Table 4. Attitudes toward whether communication courses should be setup.

\begin{tabular}{lll}
\hline Choices & Number of Students & Percentage \\
\hline Should Setup & 282 & 82.21 \\
Doesn't Matter & 44 & 12.83 \\
Unnecessary & 17 & 4.96 \\
Total & 343 & 100.0 \\
\hline
\end{tabular}

\subsection{Attitudes Toward Whether Communication Curriculum} Should Be Compulsory

Although most medical students were eager for doctorpatient communication skill training, only $33.2 \%$ of the students agreed that this course should be a compulsory course. $42.3 \%$ felt that it should be an elective course, and 
$24.5 \%$ thought it should not be a separate course, should be interspersed in medical courses and clinical practice (see Table 5).

Table 5. Attitudes toward whether communication curriculum should be compulsory.

\begin{tabular}{llll}
\hline Choices & Number of Students & Percentage \\
\hline Elective Course & 145 & 42.27 \\
Compulsory Course & 114 & 33.24 \\
Interspersed with Other Courses & 84 & 24.49 \\
Total & 343 & 100.0 \\
\hline
\end{tabular}

\subsection{Attitudes Toward Teaching Style of the Communication} Courses

It is not difficult to see from Table 6 that, $53.7 \%$ of medical students countenanced to have the course taught through clinical case-based interactive lectures with opportunities for observing teachers more closely, 9.3\% were of the opinion that didactic formal lectures is enough, while $37.0 \%$ of them favored clinical case-based interactive lectures with opportunities for discussion in combination with didactic formal lectures.

Table 6. Attitudes toward teaching style of the communication courses.

\begin{tabular}{llll}
\hline Choices & $\begin{array}{l}\text { Number of } \\
\text { Students }\end{array}$ & Percentage \\
\hline Clinical Case-Based Interactive Lectures & 184 & 53.64 \\
Didactic Formal Lectures & 32 & 9.33 \\
Combination of Both Above & 127 & 37.03 \\
Total & 343 & 100.0 \\
\hline
\end{tabular}

\section{Discussion}

In recent years, "unprecedented" tense relationship between doctor-patients exerted very negative effects on both doctors and patients in China [3, 19, 20]. The failure of doctors to communicate adequately with their patients is one of the major reasons that medical disputes arise $[19,21]$. Both doctors and patients should ponder upon how to alleviate it. Globally, accreditation bodies for undergraduate medical education have begun to recommend the incorporation of learning about the doctor-patient communication skills into medical school curricula. However, in China, education in doctor-patient communication tends to have a low priority in medical universities [22, 23]. The main aim of this study was to determine the students' assessment and preferences for learning in the subject area of doctor-patient communication skills among third-year medical school students from Fourth Military Medical University, to provide thoughts for medical education reform.

From the results of our survey, it is not difficult to find that the majority of medical students hold unoptimistic view on the current doctor-patient relationship in China. It is needless to say that, to fundamentally improve the doctor-patient relationship, we need to reform the medical system, improve the quality of medical care, and strengthen the management of the legal system [24]. However, the first important step is undoubtedly to improve the communication ability of medical students [25]. The surveyed data demonstrated that $98.3 \%$ of the students thought that good doctor-patient communication help to reduce the incidence of medical disputes. This result is supported by some systematic review of randomized clinical trials that confirmed a positive influence of doctor-patient communication on health outcomes [26, 27, 28]. Moreover, our data also indicted that less than $20 \%$ of medical students felt that they have the ability to communicate effectively with patients. Therefore, it is imperative to strengthen doctor-patient communication skills for medical students in China.

For a long time, communication in medical school curricula in China was incorporated informally as an unimportant part of medical course, without a specific or intense focus on skills of communication training. Our survey showed that the majority of students believe that the doctor-patient communication curriculum is essential and are eager for training. They expect that the courses be offered through the combination of theory with practice. This could be done through a variety of efforts. On one hand, medical employees from the hospital could be invited regularly to present interactive lectures on communication skills, discuss clinical cases with students. The contents will cover the theoretical principles of communication as well as locating those principles into the specific context of clinical cases. Small group discussions with constructive feedback will be organized where students are encouraged to discuss different types of communication. On the other hand, as learning from experience is a natural form of learning, extracurricular activities should be carried out. In these situations, students will be allowed to selectively simulate the role of doctors or patients, so as to let students feel the psychological needs and emotions in the scene. In addition, more opportunity will be offered to students to observe how the medical professors communicate with patients. All these strategies together will help medical students to easily grasp the doctor-patient communication skills.

\section{Conclusion}

Good communication between doctors and patients is an important component of the medical care. In spite of the remarkable contributions of medicine to the health of the public, there is actually increased rather than decreased dissatisfaction of the public with doctors in China. In the face of this complicated medical environment, enhancing the medical students' ability of doctor-patient communication would definitely help to promote the establishment of the harmonious doctor-patient relationship and reduce the incidence of medical disputes. Much more attention should be given to doctor-patient communication skill training when developing new medical curricula. The approach for such training should not be based upon didactic teaching styles, but could be addressed through interactive lectures or group 
workshops and through the observation within the context of real life clinical situations. This survey adds weight to the argument that communication skills should take up a greater part of medical education.

\section{Acknowledgement}

Da Liu and Longwen Xu contribute equally to this paper. This work was supported by Fourth Military Medical University under grant YZNKJG04.

\section{References}

[1] Solomon, J. 2008. "How strategies for managing patient visit time affect physician job satisfaction: a qualitative analysis." Review of. $J$ Gen Intern Med 23 (6): 775-80. doi: $10.1007 / \mathrm{s} 11606-008-0596-y$.

[2] Zgierska, A., D. Rabago, and M. M. Miller. 2014. "Impact of patient satisfaction ratings on physicians and clinical care." Review of. Patient Prefer Adherence 8: 437-46. doi: 10.2147/PPA.S59077.

[3] Wu, D., Y. Wang, K. F. Lam, and T. Hesketh. 2014. "Health system reforms, violence against doctors and job satisfaction in the medical profession: a cross-sectional survey in Zhejiang Province, Eastern China." Review of. BMJ Open 4 (12): e006431. doi: 10.1136/bmjopen-2014-006431.

[4] Lim, M. K., H. Yang, T. Zhang, Z. Zhou, W. Feng, and Y. Chen. 2004. "China's evolving health care market: how doctors feel and what they think." Review of. Health Policy 69 (3): 329-37. doi: 10.1016/j.healthpol.2004.01.001.

[5] Tucker, J. D., Y. Cheng, B. Wong, N. Gong, J. B. Nie, W. Zhu, M. M. McLaughlin, et al. 2015. "Patient-physician mistrust and violence against physicians in Guangdong Province, China: a qualitative study." Review of. BMJ Open 5 (10): e008221. doi: 10.1136/bmjopen-2015-008221

[6] Howe, E. G. 2015. "How to Retain the Trust of Patients and Families When We Will Not Provide the Treatment They Want." Review of. J Clin Ethics 26 (2): 89-99.

[7] Xu, P., Z. Fan, T. Li, L. Wang, Q. Sun, X. Du, B. Lian, and L. Zhang. 2015. "Preventing surgical disputes through early detection and intervention: a case control study in China." Review of. BMC Health Serv Res 15: 5. doi: 10.1186/s12913014-0671-5

[8] Zengin, S., B. Al, E. Yavuz, G. Kursunkoseler, R. Guzel, M. Sabak, and C. Yildirim. 2014. "Analysis of complaints lodged by patients attending a university hospital: a 4-year analysis." Review of. $J$ Forensic Leg Med 22: 121-4. doi: 10.1016/j.jflm.2013.12.008

[9] Irvine, D. H. 2007. "Everyone is entitled to a good doctor." Review of. Med J Aust 186 (5): 256-61.

[10] Singh, M. 2015. "Communication as a Bridge to Build a Sound Doctor-Patient/Parent Relationship." Review of. Indian J Pediatr. doi: 10.1007/s12098-015-1853-9

[11] Ellison, D. 2015. "Communication skills." Review of. Nurs Clin North Am 50 (1): 45-57. doi: 10.1016/j.cnur.2014.10.004

[12] Labrie, N., and P. J. Schulz. 2014. "Does argumentation matter? A systematic literature review on the role of argumentation in doctor-patient communication." Review of. Health Commun 29 (10): 996-1008. doi: 10.1080/10410236.2013.829018.

[13] Steihaug, S., P. Gulbrandsen, and A. Werner. 2012. "Recognition can leave room for disagreement in the doctorpatient consultation." Review of. Patient Educ Couns 86 (3): 316-21. doi: 10.1016/j.pec.2011.06.011.

[14] Carvalho, I. P., R. Ribeiro-Silva, V. G. Pais, M. FigueiredoBraga, I. Castro-Vale, A. Teles, S. S. Almeida, and R. MotaCardoso. 2010. "[Teaching doctor-patient communication - a proposal in practice]." Review of. Acta Med Port 23 (3): 527-32.

[15] Loue, S., A. Wilson-Delfosse, and K. Limbach. 2015. "Identifying Gaps in the Cultural Competence/Sensitivity Components of an Undergraduate Medical School Curriculum: A Needs Assessment." Review of. J Immigr Minor Health 17 (5): 1412-9. doi: 10.1007/s10903-014-0102-z.

[16] Sijstermans, R., M. W. Jaspers, P. M. Bloemendaal, and E. M. Schoonderwaldt. 2007. "Training inter-physician communication using the Dynamic Patient Simulator." Review of. Int $J$ Med Inform 76 (5-6): 336-43. doi: 10.1016/j.ijmedinf.2007.01.007.

[17] Miyasaka, M., A. Akabayashi, I. Kai, and G. Ohi. 1999. "An international survey of medical ethics curricula in Asia." Review of. J Med Ethics 25 (6): 514-21.

[18] Chen, W., S. C. Liao, C. H. Tsai, C. C. Huang, and C. C. Lin. 2008. "Clinical skills in final-year medical students: the relationship between self-reported confidence and direct observation by faculty or residents." Review of. Ann Acad Med Singapore 37 (1): 3-8.

[19] He, A. J. 2014. "The doctor-patient relationship, defensive medicine and overprescription in Chinese public hospitals: evidence from a cross-sectional survey in Shenzhen city." Review of. Soc Sci Med 123: 64-71. doi: 10.1016/j.socscimed.2014.10.055.

[20] Lin, X., M. Wang, Y. Zuo, M. Li, S. Zhu, Y. Zheng, M. Yu, and E. L. Lamoureux. 2014. "Health literacy, computer skills and quality of patient-physician communication in Chinese patients with cataract." Review of. PLoS One 9 (9): e107615. doi: 10.1371/journal.pone.0107615.

[21] Dai, Q. 2003. "Informed consent in China: status quo and its future." Review of. Med Law Int 6 (1): 53-71.

[22] Jian, W., Z. Qi, and D. Xin. 2011. "Preliminary research in the application of integrated learning and teacher-centredness in undergraduate education in China." Review of. Med Teach 33 (4): e178-85. doi: 10.3109/0142159X.2011.545844.

[23] Huang, L., Q. Cai, L. Cheng, R. Kosik, G. Mandell, S. J. Wang, G. T. Xu, and A. P. Fan. 2014. "Analysis of curricular reform practices at Chinese medical schools." Review of. Teach Learn Med 26 (4): 412-9. doi: 10.1080/10401334.2014.910463.

[24] Coleman, M., D. Dexter, and N. Nankivil. 2015. "Factors Affecting Physician Satisfaction and Wisconsin Medical Society Strategies to Drive Change." Review of. WMJ 114 (4): 135-42.

[25] Qu, B., Y. Zhao, and B. Sun. 2010. "Evaluation of residents in professionalism and communication skills in south China." Review of. Saudi Med J 31 (11): 1260-5. 
[26] Hamine, S., E. Gerth-Guyette, D. Faulx, B. B. Green, and A. S. Ginsburg. 2015. "Impact of mHealth chronic disease management on treatment adherence and patient outcomes: a systematic review." Review of. J Med Internet Res 17 (2): e52. doi: 10.2196/jmir.3951.

[27] Kannisto, K. A., M. H. Koivunen, and M. A. Valimaki. 2014. "Use of mobile phone text message reminders in health care services: a narrative literature review." Review of. $J$ Med Internet Res 16 (10): e222. doi: 10.2196/jmir.3442.
[28] Stacey, D., J. Kryworuchko, C. Bennett, M. A. Murray, S. Mullan, and F. Legare. 2012. "Decision coaching to prepare patients for making health decisions: a systematic review of decision coaching in trials of patient decision AIDS." Review of. Med Decis Making 32 (3): E22-33. doi: 10.1177/0272989X12443311. 